Significado cultural del "Conjunto Monumentario San Juan" en la ciudad de Bayamo (Cuba). El doble discurso en las voces de los comunitarios

Yania Socarrás Montejo - Diurkis Yarenis Madrigal León - Alisa Natividad Delgado Tornes

páginas / año 13 - n 33 Septiembre - Diciembre / ISSN 1851-992X/ 2021

http://revistapaginas.unr.edu.ar/index.php/RevPaginas

DOI: $10.35305 /$ rp.vi33.555

\title{
Significado cultural del "Conjunto Monumentario San Juan" en la ciudad de Bayamo (Cuba). El doble discurso en las voces de los comunitarios
}

\author{
Cultural significance of the "San Juan Monumental Complex" in \\ the city of Bayamo (Cuba). The double discourse in the voices of \\ the community members
}

\author{
Yania Socarrás Montejo \\ Centro Provincial de Patrimonio Provincia Granma (Cuba) \\ yaniasocarras@nauta.cu \\ Diurkis Yarenis Madrigal León \\ Universidad de Granma (Cuba) \\ dmadrigall@udg.co.cu \\ Alisa Natividad Delgado Tornes \\ Departamento de Gestión Sociocultural para el Desarrollo, \\ Universidad de Granma (Cuba) \\ adelgadot@udg.co.cu
}

\begin{abstract}
Resumen
El "Conjunto Monumentario San Juan" conformado como sitio histórico y patrimonial, constituye un símbolo de identidad local en la ciudad de Bayamo, provincia Granma (Cuba); por la multiplicidad en sus funciones adquiere preeminencia en el devenir cultural de la ciudad. De forma contradictoria se advierten amenazas a su carácter legendario y sagrado en el medio comunitario; lo cual incitó a la realización de un estudio científico, con el objetivo de analizar la polémica en torno al significado cultural del sitio, teniendo en cuenta criterios, pautas de interés desde las voces de los comunitarios. Se utilizó un análisis metodológico basado en la triangulación cualitativa y cuantitativa por métodos, datos y técnicas de investigación, para descubrir posicionamientos de vida encubiertos detrás de comportamientos y expresiones comunitarias. Los resultados indicaron lecturas diversas en cuanto al significado cultural del sitio, matizado principalmente por la diferencia entre los grupos etarios, las pautas culturales y el nivel de conocimiento adquirido. El análisis resultó válido para la actual política cultural, en medio de una coyuntura que precisa afianzar el sentimiento de pertenencia y responsabilidad con el patrimonio de la nación; máxime en Bayamo, territorio insigne donde se acrisoló y matizó el carácter patrio de la nacionalidad cubana.
\end{abstract}

Esta obra está sujeta a la Licencia Reconocimiento-NoComercial-CompartirIgual 4.0 Internacional de Creative Commons. http://creativecommons.org/licenses/by-nc-sa/4.0/

(cc) BY-NC-SA 


\title{
Yania Socarrás Montejo - Diurkis Yarenis Madrigal León - Alisa Natividad Delgado Tornes
}

\section{Palabras Clave}

Conjunto Monumentario San Juan; sitio histórico; patrimonio cultural; significados culturales; ciudad de Bayamo.

\begin{abstract}
The "San Juan Monumental Complex" formed as a historical and patrimonial site, constitutes a symbol of local identity in the city of Bayamo, Granma province (Cuba); Due to the multiplicity of its functions, it acquires preeminence in the cultural evolution of the city. In a contradictory way there are threats to its legendary and sacred character in the community environment; which prompted a scientific study to be carried out, with the aim of analyzing the controversy around the cultural meaning of the site, taking into account criteria, guidelines of interest from the voices of the community. A methodological analysis based on qualitative and quantitative triangulation by research methods, data and techniques were used to discover hidden life positions behind community behaviors and expressions. The results indicated diverse readings regarding the cultural significance of the site, nuanced mainly by the difference between age groups, cultural guidelines and the level of knowledge acquired. The analysis was valid for the current cultural policy, in the midst of a situation that needs to strengthen the feeling of belonging and responsibility with the nation's heritage; especially in Bayamo, a distinguished territory where the national character of Cuban nationality was clarified and nuanced.
\end{abstract}

\section{Keywords}

San Juan Monumental Complex; historical site; cultural heritage;cultural meanings; city of Bayamo.

\section{Introducción}

El estudio del patrimonio cultural sigue siendo un tema céntrico en las investigaciones actuales, a pesar del creciente interés internacional por otras materias representativas de la llamada Era Digital. La realidad de hoy bien sentida por lo que fuimos y lo que somos, indica que la herencia como significado de los pueblos mantiene su fuerza vital; por tanto, no deja de ser una prioridad académica frente al reto devenido por los efectos de la globalización, los modismos y las formas diferentes de invasión cultural.

El patrimonio afianza y sostiene la cultura de los pueblos, de ahí la necesidad de su conservación. Actualmente se multiplica los esfuerzos por parte de las distintas organizaciones internacionales encargadas de velar por la defensa del patrimonio en términos legales, particularmente de la UNESCO, quien aboga por una conciencia de protección internacional. Con ese empeño, tributan en gran medida las Cartas y Convenciones Internacionales ${ }^{1}$, en tanto, el patrimonio es recurso no renovable y altamente comprometido con los procesos identitarios.

\footnotetext{
1 Se reconocen las cartas internacionales: Atenas (1934); Venecia (1964); Burra (1979); Florencia (1981); Washington (1987); Cracovia (2000); ICOMOS (1994,2003). Además de documentos: Recomendación sobre la conservación de los bienes culturales (1968); Convención del Patrimonio Mundial (1975); Convención de Granada (1985), Normas de Quito (1987).
} 


\section{Significado cultural del "Conjunto Monumentario San Juan" en la ciudad de Bayamo (Cuba). El doble discurso en las voces de los comunitarios}

En Cuba también se aprecia una trayectoria histórica que revela la contribución a favor del patrimonio. Desde la primera mitad del siglo XX, constan estipulaciones en la Constitución del 1940 que involucran al Estado en su conservación. No obstante, el mayor compromiso direccionado al marco legal, se alcanza con el triunfo de la Revolución Cubana, un contexto explícito de aprobación y puesta en práctica de varias leyes y decretos que así lo confirman².

La legislación cubana en defensa del patrimonio cultural ofrece relevancia a los valores históricos, artísticos y socioculturales. Actualmente prevalece un trabajo coordinado con las Oficinas de Monumentos y Sitios Históricos pertenecientes a las Direcciones Provinciales de Patrimonio Cultural del país, que tienen como una de sus funciones realizar el estudio sistemático de los sitios y de sus valores, al tiempo que proponen proyectos de conservación. También se estipula el enfrentamiento a cualquier práctica nociva provocada por la sociedad, o la erosión medioambiental. En ese escenario crecen las investigaciones vinculadas con el conocimiento que aporta el bien patrimonial, la importancia en la configuración de la memoria e identidad colectiva. Por lo general, los resultados aluden a los valores que poseen los bienes según su distinción cultural, ya sea histórica, artística, estética, científica, etc., identificando en ellos, las características valorativas de los objetos y las formas de protección, conservación, y resguardo básicamente bajo el cuidado institucional y a lo sumo gubernamental. Sin embargo, resultan menos puntuales aquellos estudios direccionados a la defensa del patrimonio, intencionando la participación de la comunidad.

Estamos en presencia de una necesidad impostergable, en tanto, el patrimonio perdurará en dependencia de la impronta que le otorguen los actores sociales, principales protagonistas en el reconocimiento del bien patrimonial. En ese sentido, se potencia la defensa y protección, en la medida que permanece como parte de experiencias sentidas, adquiridas y construidas al interior de la comunidad; sin embargo, mirando la dinámica de vida y sus consecuentes transformaciones, no es posible descuidar aspectos como las diferencias de tipo sociocultural, contextual, coyuntural y con ello las valoraciones, percepciones y representaciones que los actores sociales asumen desde sus conocimientos y visión de vida.

Si bien en Cuba existe todo un sistema de protección y reconocimiento del patrimonio como baluarte de la identidad cultural, todavía se necesitan formas estratégicas para lograr un trabajo coordinado de conciliación entre los diferentes factores que intervienen en la gestión patrimonial. Es preciso que la comunidad instituya su rol como actor importante en la conservación del legado cultural; en tanto, las voces de los comunitarios también descubren significados, y con ello expresan formas de participación, máxime si están avaladas por el conocimiento, la concientización y el compromiso de la comunidad.

\footnotetext{
2 Entre otras: Ley No.1 Ley de Protección al Patrimonio Cultural y No.2 Ley de Monumentos Nacionales y Locales (1977), Ley No.62 Código Penal (1987) y Ley 81 Del Medio Ambiente.
} 


\section{Yania Socarrás Montejo - Diurkis Yarenis Madrigal León - Alisa Natividad Delgado Tornes}

En ese escenario se distingue una tarea que sigue siendo prioridad en la agenda académica internacional: "comprender el significado del patrimonio en sus diferentes acepciones, teniendo en cuenta la impronta de la comunidad".

\section{El significado cultural. Breve disquisición teórica}

En las últimas décadas del siglo XX son más puntuales los estudios en torno al patrimonio y su significado cultural. En ese ámbito se reconocen importantes resultados que discurren en torno a la identificación del bien patrimonial, teniendo en cuenta la complejidad que encierra el significado; es el caso de Martin Barbero (1991); Pierre Bourdieu (1990,1993); Jeffrey Alexander (2000); Bonfil Batalla (2000); Daniel Mato (2002); Nestor García Canclini (1993,1999); Clifford Geertz (2004) y Stuarl Hall (2004).

El debate se agudiza en la medida que varían los enfoques para determinar el bien patrimonial; así resultan varias interrogantes ¿Cuándo un bien patrimonial es significativo? ¿Cuáles son los valores que debieran comprobarse a tono con el sentido patrimonial?

Como esencia predominan varias lecturas, que van desde la necesidad de repensar las pautas que definen el bien patrimonial, el cómo identificar un sitio histórico, o cómo comprender el valor simbólico de las identidades culturales de los pueblos, teniendo en cuenta la diversidad y las diferencias. En el mismo curso, persiste el debate entre los autores para clasificar "el valor" como categoría evaluativa, a fin de establecer criterios objetivos de clasificación y análisis, así como otros indicadores de carácter artístico, histórico, urbanístico. Sin embargo, un tema peculiar adquiere relevancia: el significado otorgado al patrimonio desde las voces de la comunidad. Es aquí donde se configuran vivencias y experiencias cotidianas, convertidas en símbolos y significados estipulando sólidas huellas, por tanto, ¿es ventajoso que la comunidad estipule el significado del bien patrimonial?

Estamos en presencia de un aspecto que posee crucial interés para los cientistas sociales, en tanto, la discusión no coloca puntos conclusivos. Si bien en la gestión del patrimonio intervienen las políticas estatales, desde la lógica de las organizaciones formales, en la actualidad se precisa mayor atención a la impronta de la comunidad, desde su participación con sus saberes y prácticas culturales. Desde luego, estamos en presencia de un cambio en los últimos años, donde numerosos estudios indican la necesidad de incluir la mirada comunitaria en torno al significado de los bienes patrimoniales y su impronta para lograr transformaciones oportunas.

Al respecto, numerosos estudios indagan en la importancia de atender nuevas lógicas para interpretar el significado patrimonial, teniendo en cuenta la participación activa en el medio social. En esencia, se prioriza la participación como herramienta necesaria de gestión para garantizar la valía del patrimonio y su sustentabilidad, que implique fines e intereses de la sociedad local. Conforme con estas apreciaciones se destacan autores como: Llorenc Prats $(1998,2005) ;$ Mónica 
Significado cultural del "Conjunto Monumentario San Juan" en la ciudad de Bayamo (Cuba). El doble discurso en las voces de los comunitarios

Lacarrieu (2008); Carlos Andrés Pinassi (2013, 2016, 2017, 2018); Victoria Moron y Cristina Sánchez (2017); María Eugenia Conforti (2020).

En el curso de las intervenciones también se posiciona la necesidad de intencionar más la comunidad como principal actor en la preservación y cuidado del bien patrimonial. Al decir de Carlos Andrés Pinassi, se precisa del compromiso de los políticos responsables en la materia de encaminar verdaderas propuestas de concientización patrimonial, que trabajen sobre objetos, manifestaciones, y los propios pobladores, induciendo un cambio en el comportamiento del consumo cultural y, por lo tanto, en el conocimiento y valorización de su espacio de vida 3 .

Evidentemente son temas que, por su vigencia, siguen demandando nuevas formas de gestionar el patrimonio cultural, ello implica mayor esfuerzo desde las instancias académicas para develar problemáticas y ofrecer alternativas más eficaces. Al respecto llama la atención los procesos identitarios recurrentes en América Latina, escenario donde Cuba, país centroamericano, también presenta sus especificidades.

Ciudad de Bayamo (Cuba). El sitio histórico “Conjunto Monumentario San Juan" como símbolo de identidad cultural.

En Cuba, resulta importante el valor que adquiere el patrimonio cultural, máxime en Granma provincia oriental que atesora un porciento importante de sitios con relevancia histórica nacional; de esa amplia producción, la ciudad de Bayamo declarada Monumento Nacional, conserva 119 sitios históricos.

\section{Mapa de la República de Cuba (Fig.1)}

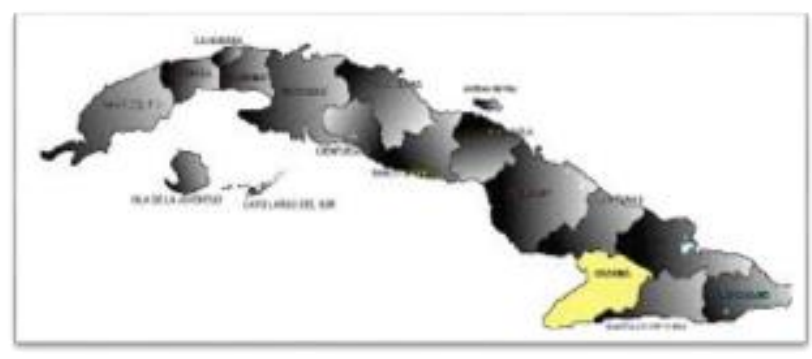

Fuente: Autoras

Localización de la Provincia Granma y sus municipios (Fig.2)

\footnotetext{
3 Carlos A. Pinassi. "Valorización social del patrimonio cultural de la ciudad de Bahía Blanca. La mirada de los residentes adultos”. Párrafos Geográficos, Vol. XVI, N¹, 2017, p. 114.
} 


\section{Yania Socarrás Montejo - Diurkis Yarenis Madrigal León - Alisa Natividad Delgado Tornes}

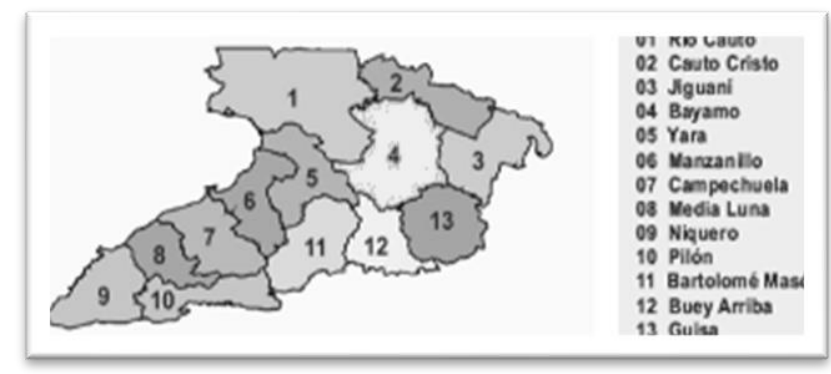

\section{Fuente: Autoras}

Una indagación más local, pensada en Bayamo como ciudad, muestra resultados sobre la cultura patrimonial que emana de las vivencias acaecidas en el territorio. En Bayamo, se acrisoló el carácter patrio de la nacionalidad cubana, nació el Himno Nacional y le pertenece el mérito glorioso de iniciar la Primera Guerra de Liberación Nacional el 10 de octubre de 1868.

\section{Localización de la ciudad de Bayamo. 2019. (Fig. 3)}

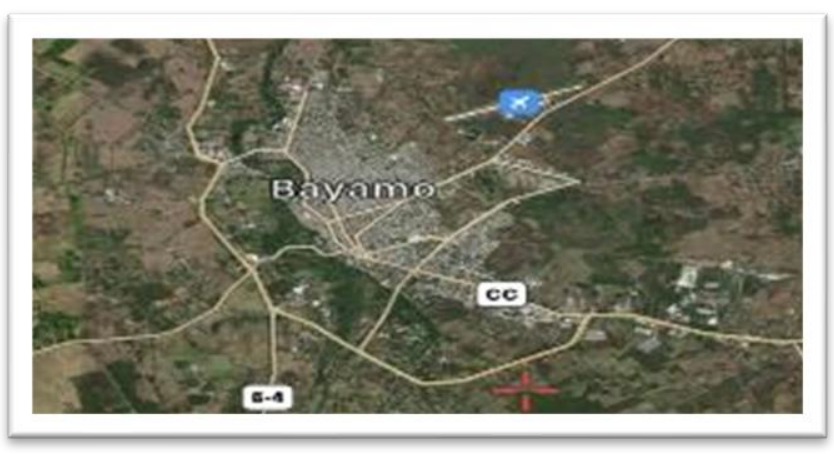

Fuente: Autoras

Bayamo como ciudad histórica, resulta insigne por la preeminencia de sus hijos para el llamado a la libertad, adquiere un lugar trascendental, que la sella como tierra de Cubanía y patriotismo demostrado. En este contexto, prevalece el énfasis por entender el significado de calles, plazas, barrancas y parques incluyendo espacios públicos como la necrópolis de la ciudad 4 .

\footnotetext{
${ }^{4}$ Investigaciones sobre la localidad han sido relevante por los historiadores Idelmis y Eduardo Mari (2005). También constan resultados sobre la Necrópolis, a cargo del historiador de la ciudad Ludín Fonseca (2005) y Yania Socarrás (2005).
} 
Significado cultural del "Conjunto Monumentario San Juan" en la ciudad de Bayamo (Cuba). El doble discurso en las voces de los comunitarios

Barranca de La Lizana. Siglo XIX. (Fig. 4)

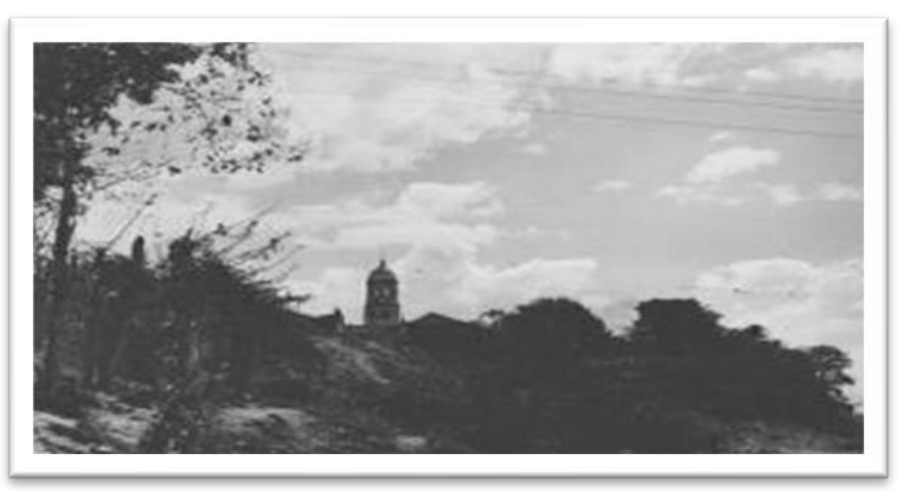

Fuente: Archivo Casa de la Nacionalidad Cubana.

Barranca La Lizana. Siglo XXI. (Fig. 5 y 6)
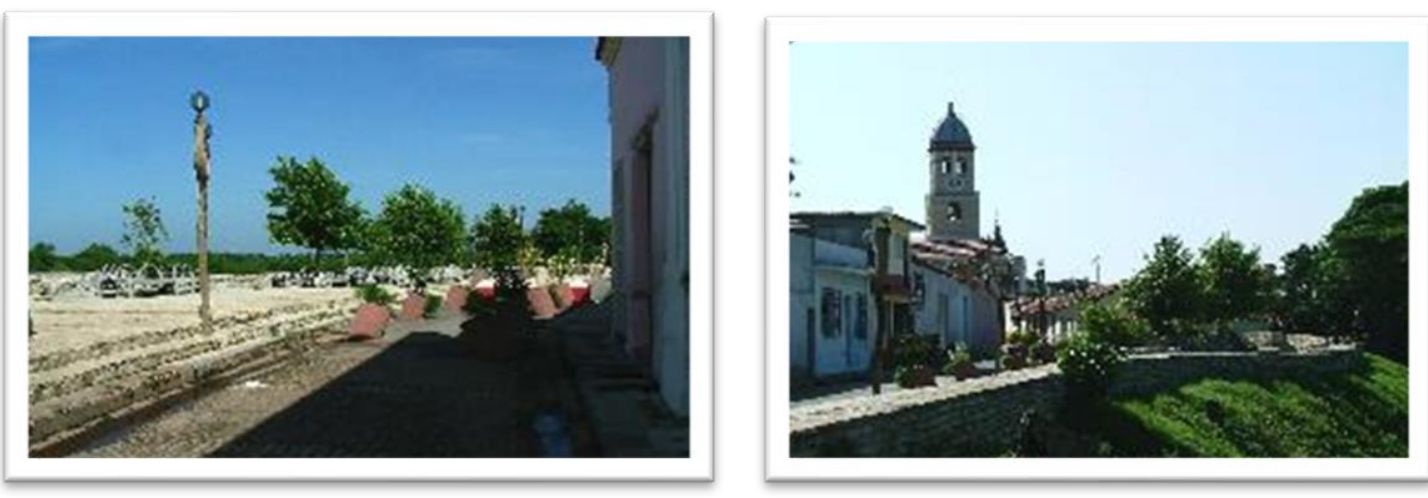

Fuente: Autoras.

Plaza de San Francisco actual Parque de Las Madres. Siglo XX (Fig. 7)

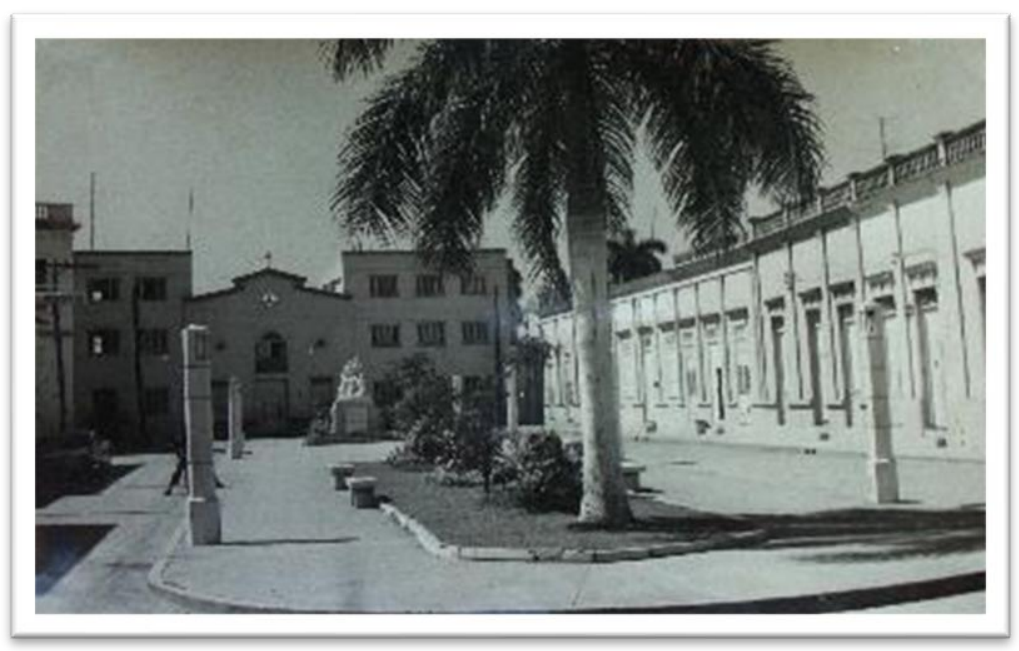

Fuente: Archivo Casa de la Nacionalidad Cubana. 
Yania Socarrás Montejo - Diurkis Yarenis Madrigal León - Alisa Natividad Delgado Tornes

Plaza del Himno, antigua Plaza de la Iglesia Mayor. (Figs. 8 y 9)
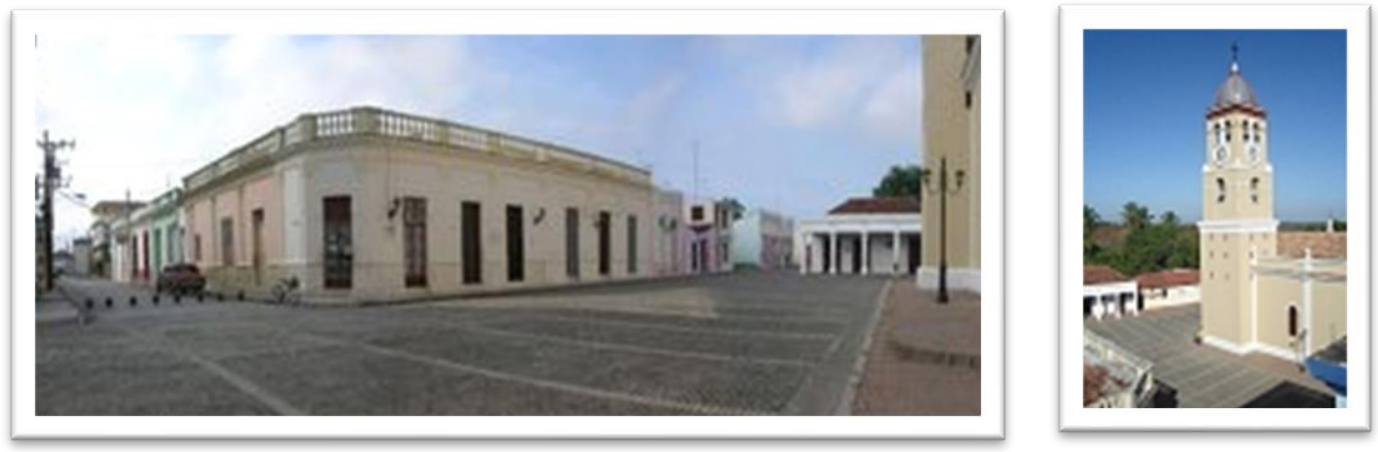

Fuente: Archivo Casa de la Nacionalidad Cubana.

Paseo Bayamés ubicado en la calle General García. (Fig. 10 y 11)
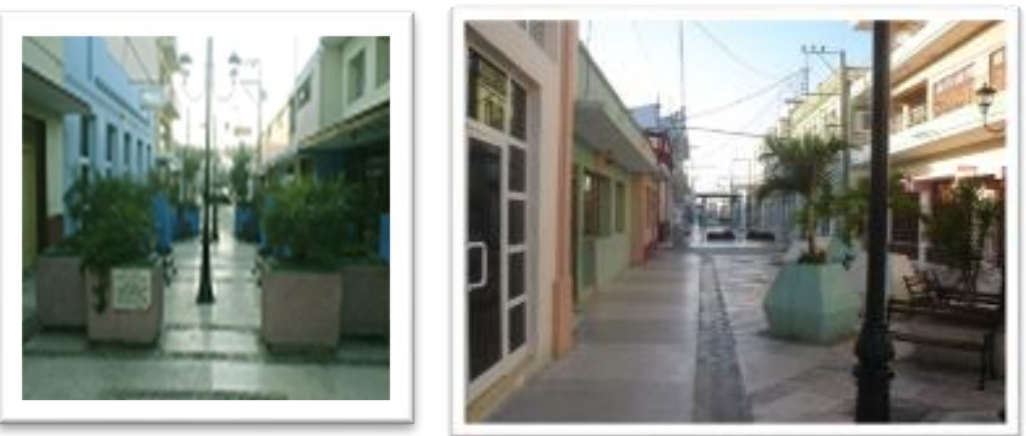

Fuente: Autoras.

Monumento a Carlos Manuel de Céspedes en la Plaza de la Revolución. (Fig. 12)

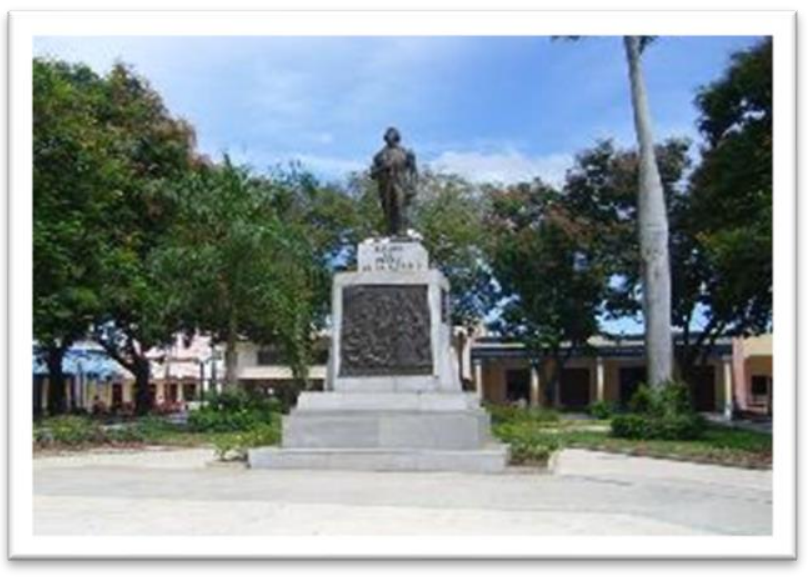

Fuente: Autoras 
Significado cultural del "Conjunto Monumentario San Juan" en la ciudad de Bayamo (Cuba). El doble discurso en las voces de los comunitarios

Monumentos funerarios de la Necrópolis de Bayamo con valores históricoartístico. (Figs. 13-15)
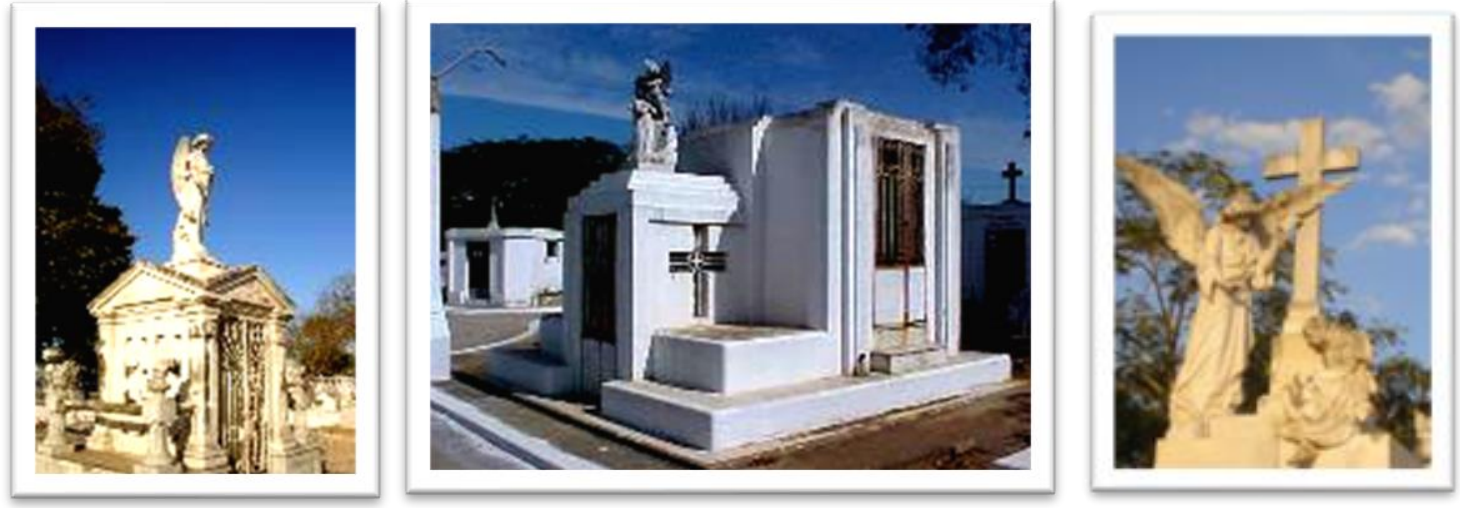

Fuente: Autoras

La pasión por la historia permanece como baluarte distintivo para los bayameses, por tal motivo, es posible atender un tema de identidad cultural, en la tierra que evoca cubanía. Aquí se yergue un sitio patrimonial, conocido en el devenir del tiempo por varios nombres: Iglesia San Juan Evangelista y su plaza, cementerio San Juan Evangelista o Cementerio Viejo, Retablo de los Héroes y luego Parque San Juan. Actualmente es oficial su nombre como “Conjunto Monumentario San Juan" (en lo adelante también CMSJ), según consta legalmente por la Oficina de Sitios Históricos y Monumentos.

Se encuentra emplazado en la zona de amortiguamiento de la otrora villa San Salvador de Bayamo ${ }^{5}$, actualmente Centro Histórico de la ciudad. Según su ubicación y las características de sus calles posee singular relevancia en el entramado citadino actual.

Localización del Reparto San Juan y del Conjunto Monumentario San Juan. (Fig. 16)

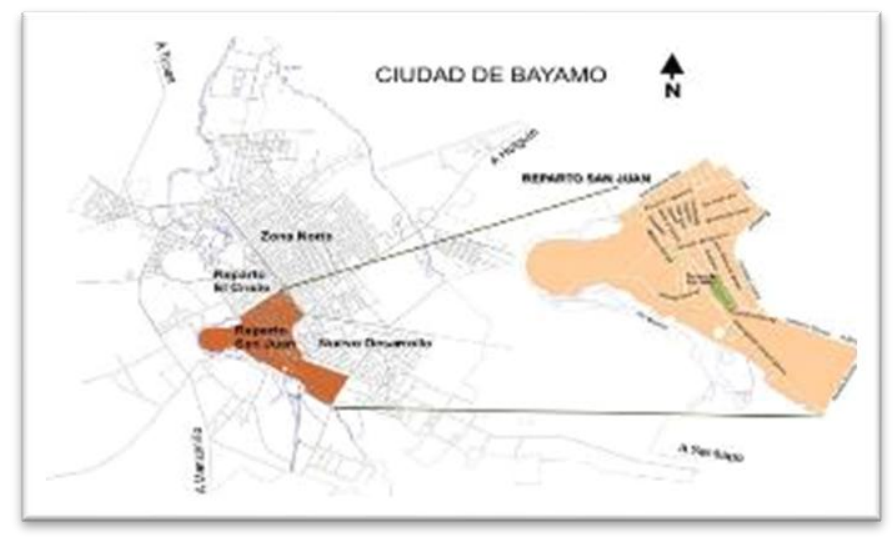

Fuente: Oficina Provincial de Monumentos y Sitios Históricos

${ }^{5}$ Villa San Salvador de Bayamo, actualmente ciudad de Bayamo y capital de la provincia Granma. 


\section{Yania Socarrás Montejo - Diurkis Yarenis Madrigal León - Alisa Natividad Delgado Tornes}

\section{Localización del Conjunto Monumentario San Juan. (Fig.17)}

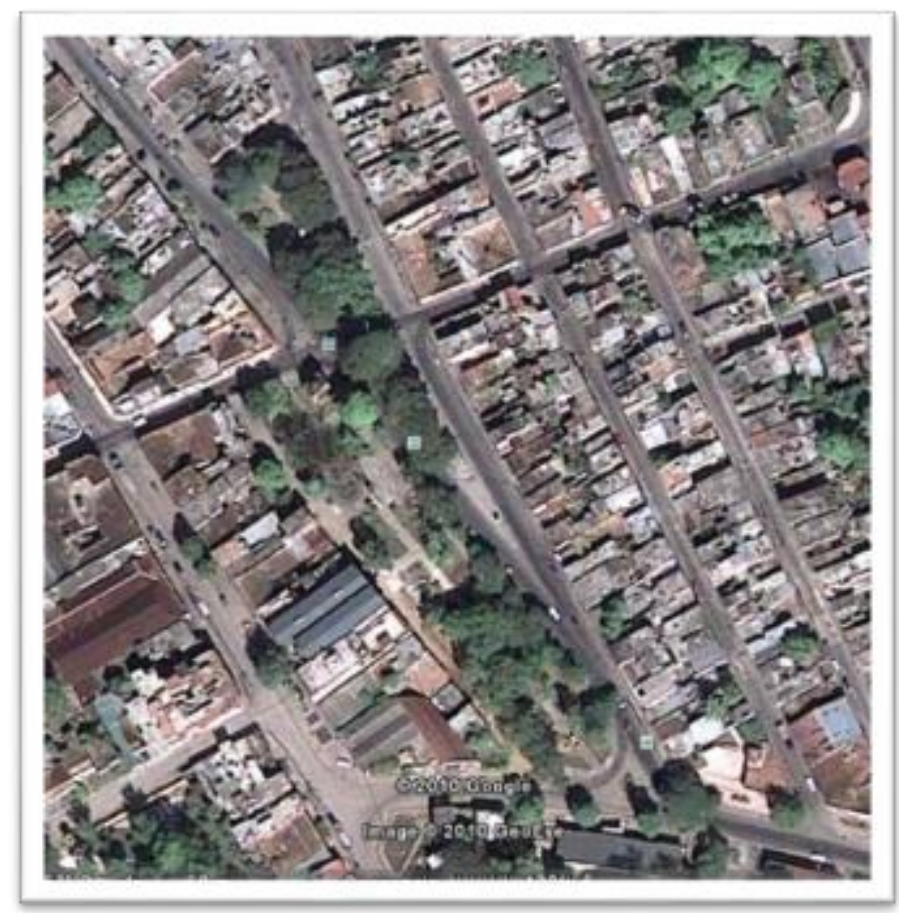

Fuente: Autoras

El CMSJ Juan está conformado por múltiples espacios con valores diversos: histórico, urbanístico, arquitectónico, artístico, social, entre otros. Devela acepciones importantes de los períodos colonial y republicano. De acuerdo con las normativas patrimoniales de la ciudad, el CMSJ, se conforma por cinco monumentos de carácter patrimonial, así figuran:

\section{La Torre de la Iglesia San Juan Evangelista (Fig. 18)}

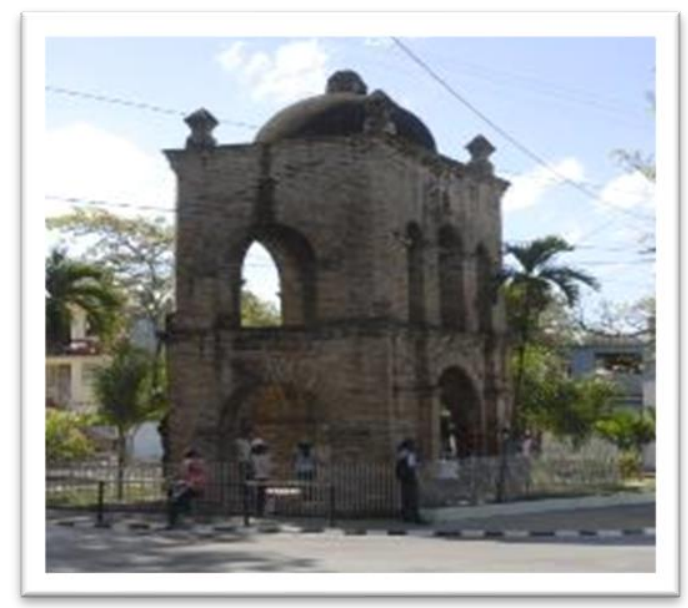

Fuente: Autoras

La Iglesia San Juan Evangelista, además de sus sacras funciones, operaba como lugar de enterramiento por la tradición europea, y adjunto, el cementerio ${ }^{6}$ homónimo. En

${ }^{6}$ El Cementerio San Juan Evangelista, también denominado Cementerio Viejo. Creado el 5 de enero de 1789 para satisfacer estas necesidades higiénico-sanitarias del poblado. Estudios afirman que la 


\section{Significado cultural del "Conjunto Monumentario San Juan" en la ciudad de Bayamo (Cuba). El doble discurso en las voces de los comunitarios}

este cementerio fueron sepultados los restos mortales de prestigiosas familias bayamesas y próceres ${ }^{7}$ de la patria como Francisco V. Aguilera y Esteban Tamayo y Tamayo.

La torre de la Iglesia San Juan Evangelista, vestigio de la labor y amplia aceptación durante la etapa colonial, llegó a desempeñar las funciones de iglesia principal. Después del incendio de 1869, por su estado ruinoso, su torre se convirtió en el Pórtico del Cementerio.

El Monumento a Francisco Vicente Aguilera. (Fig. 19)

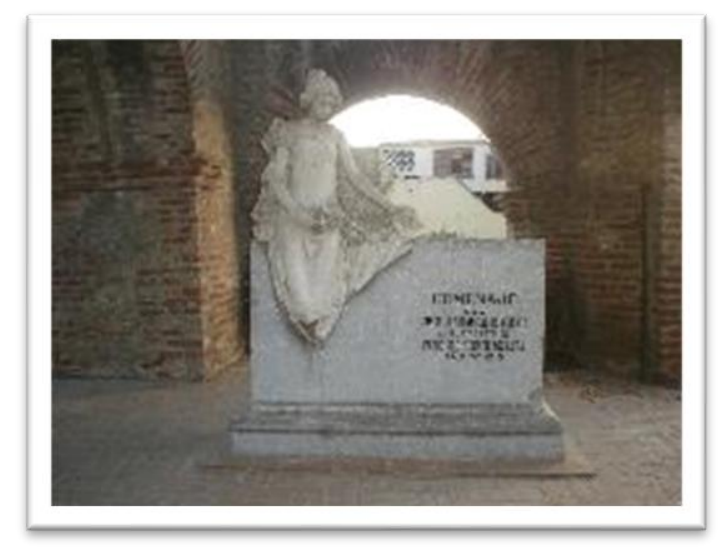

\section{Fuente: Autoras}

Monumento dedicado a Francisco V. Aguilera. Obra de Ugo Luisi (1910). Único vestigio conservado del otrora cementerio San Juan Evangelista. Fue donado por el Consejo Provincial de Oriente de Santiago de Cuba para la ciudad de Bayamo en 1913, con el objetivo de dignificar su tumba, en su ciudad natal. Se trata de una efigie femenina que porta en sus manos un ramo de rosas, su mirada triste y su postura reflexiva, invita a meditar en torno a la muerte. Algunos proyectos de conservación anhelan la permanencia de este monumento de mármol de Carrara como exponente de la escultura funeraria bayamesa.

$\checkmark$ Retablo de los Héroes Bayameses. Vistas frontal y posterior. (Figs. 20 y 21)
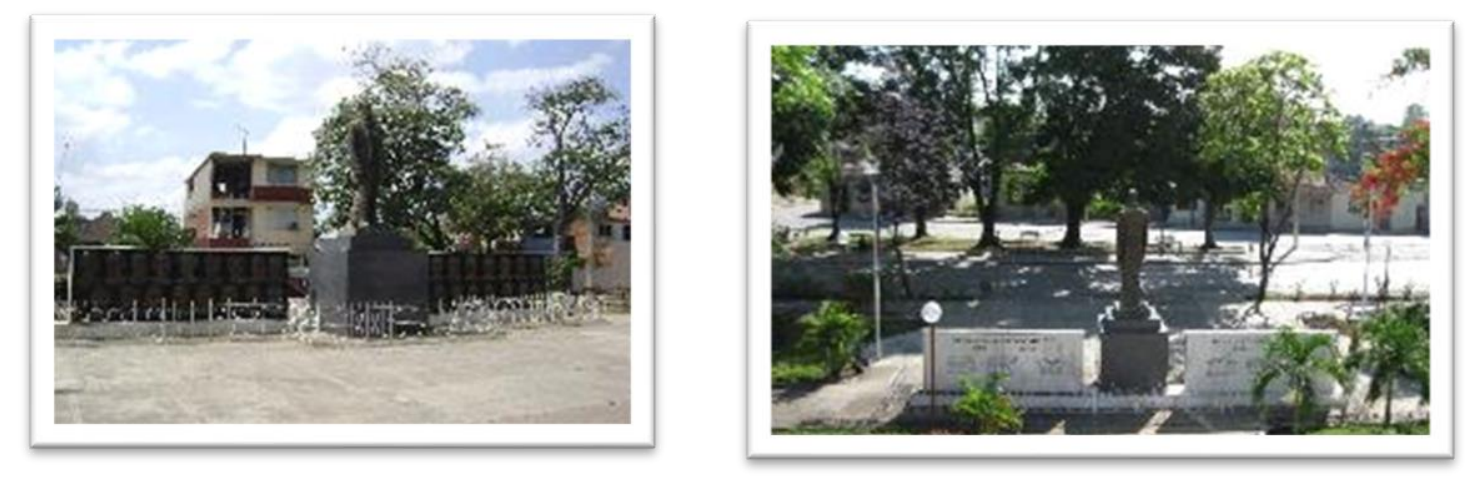

Fuente: Autoras

cruda realidad epidémica de la villa a finales de 1797 e inicios de 1798, condujo a la creación del cementerio, aun cuando este no cumpliera debidamente con las normativas para su uso.

7 Se destacan patriotas bayameses, exponentes en luchas por la Independencia de Cuba: Francisco V. Aguilera y Tamayo (encabezó el primer Comité Revolucionario de Bayamo) y Esteban Tamayo y Tamayo. 


\section{Yania Socarrás Montejo - Diurkis Yarenis Madrigal León - Alisa Natividad Delgado Tornes}

Retablo ${ }^{8}$ de los Héroes Bayameses. Obra de Sergio López Mesa (1955). Resulta construcción conmemorativa y mausoleo a la memoria de Francisco V. Aguilera y a otros 33 próceres de las luchas independentistas. Escolta en su interior los restos mortales de Francisco V. Aguilera, traídos desde los Estados Unidos de América como resultado de diversos reclamos del pueblo bayamés a inicios de la República. Se compone por una escultura en broce con base de granito negro, acompañada a ambos lados por dos paneles con los rostros broncíneos de patriotas destacados.

\section{$\checkmark$ Mausoleo a José Joaquín Palma (Fig. 22)}

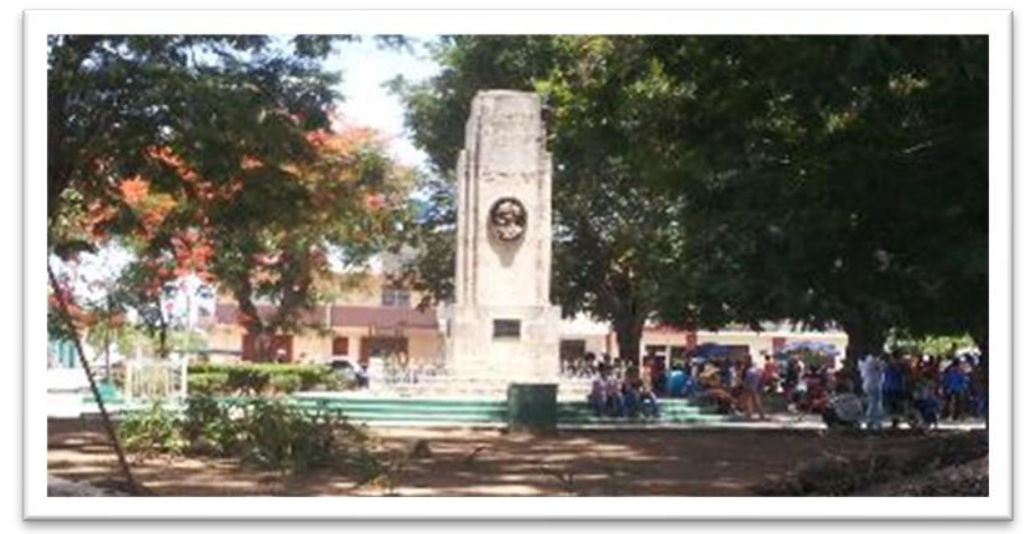

Fuente: Autoras

Esta área fue asumiendo, durante años, una connotación venerable para los bayameses ${ }^{9}$. Otros patriotas y moradores exigieron un reconocimiento honorable al lugar, ello implicó la conformación paulatina de una identidad como sitio sagrado para el reposo eterno.

Allí yergue el Mausoleo a José Joaquín Palma, obra de José Florencio Gelabert Pérez (1951). El monumento se erigió para depositar los restos mortales del poeta bayamés, traídos desde Guatemala, para atender su expresa voluntad de reposar en suelo patrio.

Tarja sobre Monolito a un Grupo del Movimiento 26 de Julio. (Fig.23)

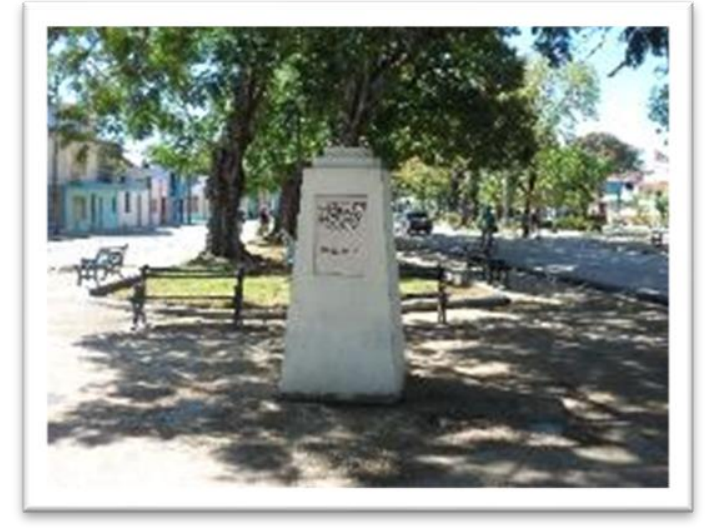

Fuente: Autoras

\footnotetext{
${ }^{8}$ Los retablos constituyen conjuntos o colecciones de figuras pintadas o de talla que representan series históricas. También referencia a una obra de arquitectura, de piedra, madera u otra materia, para decorar un altar, y por tanto, contenedor de un carácter sacro.

${ }^{9}$ Así consta en la obra literaria del bayamés José Joaquín Palma, patriota, poeta y educador. Cónsul general de Cuba en Guatemala, y quien compuso la letra del Himno Nacional de esa nación centroamericana.
} 
La tarja que descansa sobre un monolito, situada en el CMSJ, fue construida para honrar al grupo que protagonizó acciones durante el asalto al Cuartel Carlos Manuel de Céspedes, ${ }^{10}$ conocido como Movimiento 26 de Julio. ${ }^{11}$

El CMSJ es reconocido como un sitio de importancia histórica para la comunidad bayamesa al contener monumentos creados para honrar y sacralizar en un retablo a aquellos próceres destacados por su patriotismo, de ahí su denominación como Sitio Sagrado o Altar de la Patria.

A ello se suma la existencia de los conjuntos funerarios, quizás únicos en el país -y donde aún- quedan restos mortales de bayameses. La distinción también reside en el uso históricamente otorgado como un espacio clave para actos y concentraciones de carácter político, ideológico y de solemnidad para remembrar fechas trascendentales dentro de la historia de nuestra nación. ${ }^{12}$

\section{Actos conmemorativos, alegóricos a fechas históricas. (Figs. 24 y 25)}

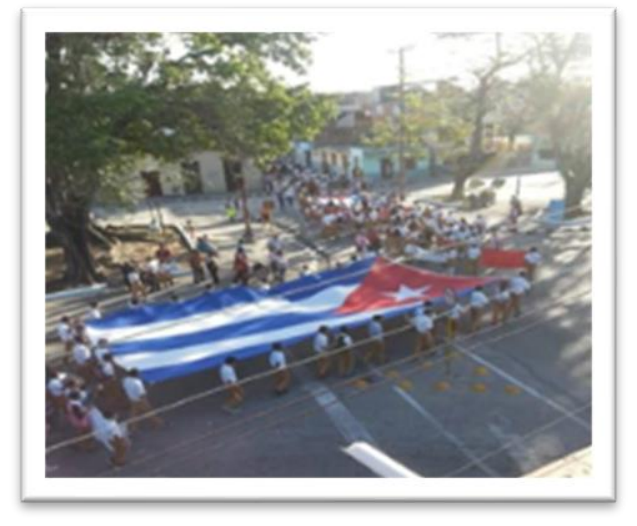

\section{Fuente: Autoras}

En alegoría con su carácter históricopatrimonial, el monumento es considerado por el Ministerio de Turismo de la provincia, como uno de los sitios de mayor interés dentro de la ciudad para ser visitado por turistas nacionales e internacionales ${ }^{13}$.

Con el advenimiento del siglo XXI, se reafirman las múltiples lecturas que

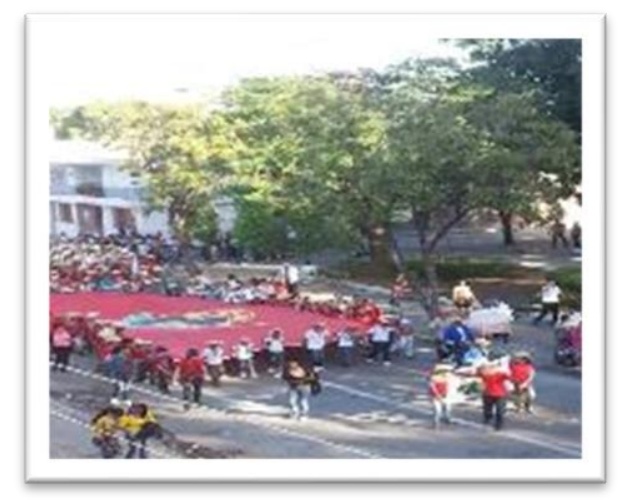

10 Cuartel Carlos Manuel de Céspedes: Lugar de acción revolucionaria, ubicado en la Ciudad de Bayamo, al igual que el Cuartel Moncada en Santiago de Cuba, fue asaltado el 26 de julio de 1953.

11 Movimiento 26 de Julio (M-26-7): Organización política y militar, creada el 12 de junio de1955 en la clandestinidad, por un grupo de revolucionarios dirigidos por Fidel Castro.

12 Se distinguen fechas significativas: 28 de enero de 1853 (para conmemorar el natalicio de José Julián Martí y Pérez, Héroe Nacional de Cuba). El 28 de octubre de 1959 (homenaje a la figura de Camilo Cienfuegos Gorriarán, desaparecido en un accidente aéreo mientras cumplía tareas de la naciente Revolución Cubana). El 23 de junio de 1821 (homenaje al patriota Francisco V. Aguilera, en ocasión a su natalicio).

13 Map Guide Granma. Travel Agencies and INFOTUR Granma. Cuba. 


\section{Yania Socarrás Montejo - Diurkis Yarenis Madrigal León - Alisa Natividad Delgado Tornes}

denotan al CMSJ como expresión de símbolo sagrado para la identidad cultural de los bayameses; sin embargo, llegan potencialmente nuevas miradas que se posesionan en contradicción con la genuina defensa del sitio como depositario de la identidad construida. Desde principios de la primera década del presente siglo XXI, se observan algunas manifestaciones ciudadanas que indican prácticas indebidas en el área que ocupa el CMSJ, siendo oportunamente denunciadas por vecinos de la comunidad, principalmente los ancianos, quienes expresan preocupación por la seguridad de los monumentos y la imagen general del entorno.

Se trata de un grupo de vecinos, que ven con indignación algunas prácticas inadecuadas en el lugar, en específico, niños y adolescentes que interactúan realizando actividades lúdicas y deportivas ${ }^{14}$ provocando el deterioro del mobiliario urbano y de los monumentos de forma general; también se muestra inconformidad con el cuidado del sauce que durante siglos ha constituido un símbolo cultural ${ }^{15}$.

La preocupación se hizo extensiva por varias vías informales y formales, que atañan a las Asambleas de Rendición de Cuentas ${ }^{16}$ del delegado del Poder Popular ante sus electores y en despacho con la Delegada de la circunscripción ${ }^{17}$; también se hizo formal la gestión ante las entidades patrimoniales, a fin de obtener respuesta acertada enfocada en la salvaguarda del conjunto monumentario.

\section{Precisiones metodológicas para el estudio del significado cultural en torno al sitio “Conjunto Monumentario San Juan”.}

Se percibe en la opinión de algunos comunitarios, la urgente atención al cuidado patrimonial del lugar, además preocupa la conservación del sitio en las manos de las nuevas generaciones. Se constata así un reclamo a favor de la preservación del patrimonio desde las voces de un sector importante de la comunidad, que exige el reconocimiento de la valía que posee el CMSJ. La realidad devela la pertinencia de una necesidad de estudio, básicamente para comprender el significado cultural que posee el CMSJ en la identidad de los comunitarios.

Para la indagación científica se implementó una estrategia de análisis metodológica pertinente a la triangulación cuantitativa y cualitativa de métodos, datos y técnicas de investigación, a fin de validar datos y descubrir esencias profundas que se esconden detrás de comportamientos y expresiones comunitarias. Se consideró oportuno comprender el mundo de los significados atribuidos al patrimonio cultural, desde las voces de los comunitarios, para comprender el uso y tenencia del

\footnotetext{
14 Realizan acciones como carreras, juegos de béisbol, futbol, tiroteos de pelotas y otros actos de bullicio inclinados a la diversión y recreación. Es importante aclarar que no hay evidencias de conductas vandálicas o de atentado explícito al daño material.

15 El sauce se sembró a petición del autor del Himno de Guatemala, José Joaquín Palma, quien en uno de sus poemas pidió tener un sauce junto a sus restos mortales.

16 Asambleas de Rendición de Cuentas: Respecta a las reuniones que realizan los electores para ser analizado frente a la Asamblea del Poder Popular (Órgano con potestad constituyente y legislativa en la República de Cuba).

17 Delegada: persona elegida por el voto libre del pueblo para representar sus intereses comunitarios.
} 


\section{Significado cultural del "Conjunto Monumentario San Juan" en la ciudad de Bayamo (Cuba). El doble discurso en las voces de los comunitarios}

sitio, así como el nivel de conocimiento que posee la comunidad a tono con los valores del CMSJ.

El universo de estudio comprendió al conjunto de vecinos de tres $\operatorname{CDR}^{18}$ 4, 5 y 11 residentes en los alrededores del CMSJ. Como unidad de análisis fue seleccionada una muestra aleatoria no probabilística del grupo de comunitarios, agrupados de acuerdo con sus características etarias: adolescentes (10-17 años), jóvenes (18-35 años), adultos (36-64 años), y adultos mayores (65 y más años). Del total de habitantes (alrededor de 350), se escogieron 150 vecinos. Fueron encuestados 50 adolescentes y jóvenes, 50 adultos, y 50 adultos mayores a quienes se le aplicaron las herramientas de investigación. Como parte de la estrategia, se conformó un seguimiento fraccionado en tres etapas de trabajo.

Primera etapa: Se indagó en la documentación referente a los valores patrimoniales atribuidos al CMSJ. Para este propósito se tuvo en cuenta la revisión documental ${ }^{19}$. Se revisó la documentación y bibliografía existente en los archivos históricos de la Casa de la Nacionalidad Cubana, el Archivo Histórico Provincial de Granma, el Archivo de la Diócesis del Santísimo Salvador de Bayamo Manzanillo, en la Dirección Provincial de Patrimonio Cultural de Granma, la Oficina de Monumentos y Sitios Históricos de Bayamo y la Dirección Provincial de Planificación Física que están relacionados con las iglesias, las plazas asociadas a estas y las funciones funerarias en la ciudad de Bayamo ${ }^{20}$.

Segunda etapa: Se implementaron varios instrumentos para la recogida de información y posterior análisis de los datos. Se emplearon herramientas para contabilizar el número de comunitarios y estadificar el porciento de cada sector poblacional. Igualmente se emplearon otras técnicas cualitativas dirigidas a la comprensión de emociones, sentimientos, y posicionamientos culturales de relevancia local.

\footnotetext{
${ }^{18}$ CDR (Comité de Defensa de la Revolución): Creado el 28 de septiembre de 1960, como respuesta del pueblo cubano al terrorismo desatado por el gobierno de Estados Unidos contra Cuba. Se organizan por cuadras, zonas, municipios, provincias y nación, reúne más de ocho millones de ciudadanos cubanos mayores de 14 años de edad, sin distinguir sexo, raza o religión. Esta organización es decisiva para combatir procesos epidémicos, limpiar y embellecer calles y locales sociales; además de brindar atención a personas vulnerables y contribuir con los procesos electorales del Poder Popular. Actualmente en la ciudad de Bayamo constan 1752 CDR.

${ }^{19}$ Lourdes de Urrutia y Graciela González. Metodología de la Investigación social 1 y 2. Selección de Lecturas. La Habana, Editorial Félix Varela, 2003, p. 124.

${ }^{20}$ Archivo Histórico de la Casa de la Nacionalidad Cubana: File Iglesias de Bayamo: Iglesia San Salvador de Bayamo, Iglesia San Juan Evangelista, Iglesia de la Luz, Iglesia de Santa Ana. Archivo Histórico Provincial de Granma: Libro de Actas No.15, p 257. (Francisco V. Aguilera, traslado de sus restos). AHPG: Fondo Gobierno Municipal (Neocolonia) Libros de Inventarios. Cámara Municipal. Leg. 180, Exp. 6616; Leg. 143 Exp. 5806, Leg. 147. Exp. 5914; Leg. 150. Exp. 5979; Leg. 155 Exp. 6064; Leg. 95 Exp. 4049; Leg. 99 Exp. 4224; Leg.110 Exp. 4664; Leg. 97 Exp. 4177; Leg. 99 exp. 4230. Leg. 119 exp. 4954; Leg. 183 Exp.6675; Leg. 184 Exp. 6683; Leg. 185 Exp. 6688. Rafael Rodríguez. Proyecto de Restauración Santísimo Salvador de Bayamo. Ed. Facultad de Arquitectura, Salvador de Bahía, Brasil, 1990.
} 


\section{Yania Socarrás Montejo - Diurkis Yarenis Madrigal León - Alisa Natividad Delgado Tornes}

La intencionalidad de los instrumentos procede con el criterio de la triangulación de métodos y técnicas de investigación. Resultó factible la utilidad de los métodos teóricos como: análisis-síntesis, histórico-lógico, en conjunto con la observación científica, en tanto, método empírico. Asimismo transcendió el uso de las siguientes técnicas de investigación ${ }^{21}$ : a) el cuestionario, b) la entrevista enfocada, c) la entrevista en profundidad y d) el grupo focal o de discusión.

La observación científica ${ }^{22}$ se realizó en torno al sitio histórico, en diferentes horarios, por varias semanas de indagación. Se observaron talleres comunitarios, para verificar expresiones y significados atribuidos al sitio. En estos casos se logró la participación de organismos e instituciones de la dirección de cultura: Dirección Provincial de Patrimonio de Granma, la Casa de la Nacionalidad Cubana, la Oficina de Monumentos y Sitios Históricos, Delegados de Circunscripción del Poder Popular, Núcleo de Zona del PCC y el INDER 23 .

La observación fue realizada en cinco momentos, durante días normales y en fechas trascendentales, y desde diferentes lugares de los alrededores del CMSJ. Ello permitió profundizar en el acercamiento a la comunidad, para registrar más que el comportamiento, el cómo piensan y sienten el sitio como parte de su identidad. Se exploró durante varios momentos formas de interacción para conocer el sentir comunitario teniendo en cuenta los reclamos que condujeron los objetivos de este estudio.

El cuestionario ${ }^{24}$ se aplicó al sector más joven de la comunidad. Se consideró la propia dinámica de la juventud, por ser un grupo etario más evasivo frente a la aplicación de técnicas grupales. Con el instrumento fue posible realizar un conjunto de preguntas de manera impersonal, de modo que los respondientes no juzgaran invadida su conducta. En concreto se precisaron interrogantes como: ¿qué conocen sobre el CMSJ?, ¿qué usos realizan de este?, ¿consideran importante su protección? Las entrevistas enfocadas ${ }^{25}$ resultaron coherentes para dialogar con algunos ancianos de la comunidad, quienes mostraron preocupación por la protección del sitio, ante situaciones creadas por los niños y adolescentes. El objetivo fue establecer un diálogo abierto exponente de las impresiones sobre el lugar, y con ello comprender sentimientos de pertenencia, recuerdos, vivencias y experiencias.

Las entrevistas en Profundidad ${ }^{26}$ se concibieron para establecer un diálogo abierto o semiestructurado con criterio de selección: fueron aplicadas a especialistas de la

\footnotetext{
21 En la disquisición de la metodología empleada en términos generales, relacionado con el enfoque, los métodos y las técnicas, fue oportuno el criterio de: Roberto Hernández, et al. (2006); Lourdes de Urrutia y Graciela González (2003); José Ignacio Ruíz (1999); Gregorio Rodríguez, et al. (2004).

${ }^{22} J o s e ́$ Ignacio Ruíz Olabuénaga. Metodología de la Investigación cualitativa. España, Universidad de Deusto, Bilbao, 1999p.124-163

23 INDER: Se nombra al Instituto Nacional de Deportes, Educación Física y Recreación en Cuba.

24 Roberto Hernández Sampier, C Fernández-Collado y $\mathrm{P}$ Baptista Lucio. Metodología de la investigación (4ta. Ed.). México. Ed. McGraw-Hill Interamericana, 2006, p. 310-339 y Gregorio Rodríguez Gómez, Javier Gil Flores, Eduardo García Jiménez. Metodología de la Investigación cualitativa. La Habana, Editorial Félix Varela, 2004, p. 310-339.

${ }^{25}$ Roberto Hernández Sampier, Op. Cit., p. 597

${ }^{26}$ Gregorio Rodríguez Gómez, Op. Cit., p. 168-184
} 


\section{Significado cultural del "Conjunto Monumentario San Juan" en la ciudad de Bayamo (Cuba). El doble discurso en las voces de los comunitarios}

Oficina de Monumentos y Sitios Históricos, cuadros de la Dirección Municipal de Comunales Bayamo y la Dirección Provincial de Patrimonio. Se procuró recoger y analizar los saberes y discursos construidos, como responsables con la protección del sitio. La entrevista en profundidad permitió ahondar en los conocimientos sobre los valores del CMSJ, e identificar los comportamientos individuales y la responsabilidad que tienen en su cuidado.

El Grupo Focal o Grupo de Discusión, ${ }^{27}$ se implementó a vecinos residentes en el medio comunitario (Figs. 26 y 27), siguiendo determinados requisitos coincidentes: ser vecinos adultos mayores de 35 años, que residieran en la circunscripción. Participaron varios presidentes de CDR, la Delegada de circunscripción, la Delegada de la FMC del área, el Coordinador de los CDR, un miembro del PCC de la circunscripción, la responsable del área de Cultura en el Grupo de Trabajo Comunitario y un combatiente de la Revolución. La dinámica se enfocó en lograr un intercambio de ideas, para comprender la significación que tiene el sitio para los comunitarios. En este debate se pudo obtener el conocimiento directo de actitudes y percepciones sobre el tema de estudio.

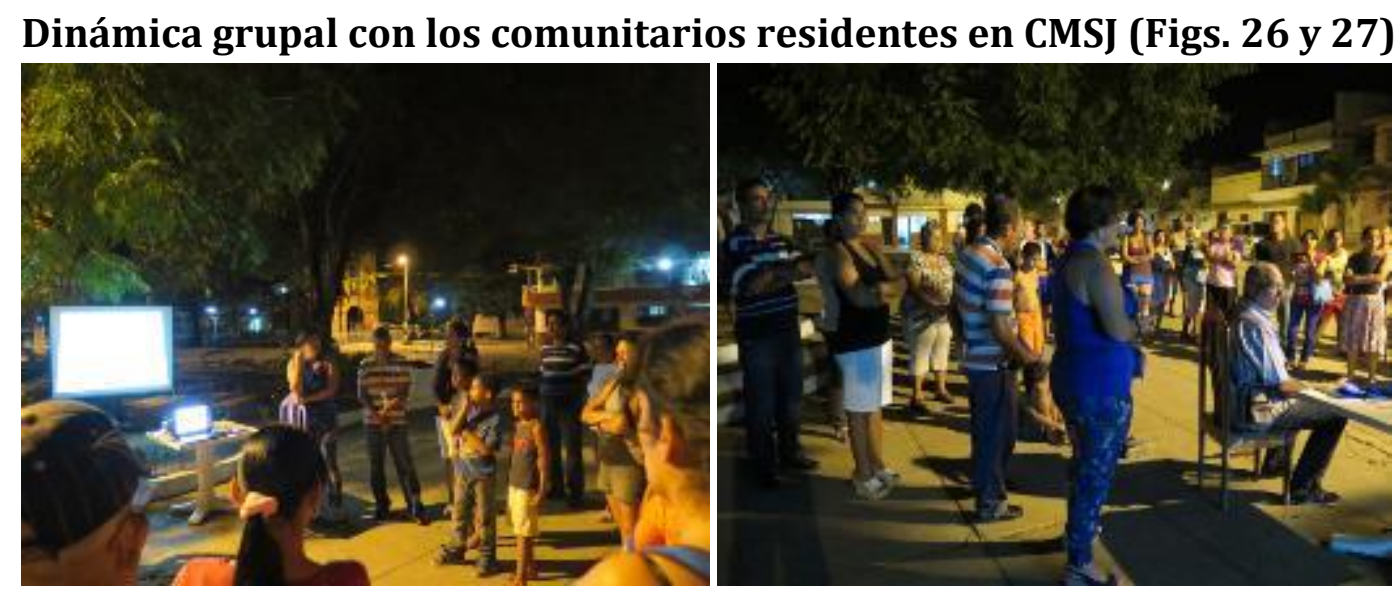

Fuente: Autoras

Tercera etapa: Direccionada al análisis de los resultados, permitió examinar los datos con énfasis en la triangulación de datos cuantitativos y cualitativos. Se consideró la información estadística de los comunitarios -según los grupos etariosy el mundo de las significaciones atribuidas de acuerdo con cada grupo poblacional. Para este caso, se realiza hincapié en la significación cultural como criterio vertebrador del análisis, en tanto, nos facilita valorar ese mundo simbólico que se construye y socializa con el paso del tiempo.

\section{El significado cultural del sitio "Conjunto Monumentario San Juan". Lecturas desde la diversidad y diferencias}

Los diferentes significados que poseen los sitios patrimoniales a pesar de ser acumulativos y cambiantes, mantienen su esencia cultural, aunque existan

${ }^{27}$ Roberto Hernández Sampier, Op. Cit., pp. 605-619 


\section{Yania Socarrás Montejo - Diurkis Yarenis Madrigal León - Alisa Natividad Delgado Tornes}

elementos diferenciadores en la identidad de una comunidad como eje, núcleo duro, sostén o zona de persistencia ${ }^{28}$.Ello demuestra que es la sociedad la que se levanta como agente activo para configurar su patrimonio cultural y establecer e identificar aquellos elementos que desea valorar y asumir como propios referentes de identidad. Así se muestra por ejemplo el CMSJ en la Ciudad de Bayamo, este se instituye como símbolo de identidad cultural, a pesar de las diferencias en los discursos que emanan desde la comunidad.

Como parte de los resultados que derivan de la metodología aplicada, se aprecian disímiles puntos que marcan lecturas diversas en cuanto al significado cultural del CMSJ, matizado principalmente por la diferencia entre los grupos etarios. Igualmente intervienen otras pautas, ajustadas por las vivencias con el pasado histórico que ennobleció a las familias residentes en el entorno, el tiempo de residencia en áreas cercanas al sitio, el nivel de conocimiento y la cultura histórica que predomina sobre la ciudad. Las apreciaciones, comentarios, y valoraciones circularon por un camino que osciló por un abanico de consideraciones:

a) Se notifica una actitud bien comprometida con el CMSJ, en las voces de los ancianos que poseen más de 70 años de vida en la comunidad. Es sorprendente el nivel de conocimiento que conservan sobre la historia del sitio y velan con orgullo cada detalle de aquellas vivencias donde sus ascendientes fueron protagonistas de los hechos acaecidos; además de saberse implícitos en muchos acontecimientos que alcanzaron repercusión en la historia y la cultura de la ciudad y la nación. Estas razones afianzan el sentimiento de pertenencia y de responsabilidad ante la protección, el cuidado y la salvaguarda del complejo patrimonial al decir de ellos como "Altar de la Patria Grande".

Este grupo defiende y aboga por actitudes más comprometidas por la conservación del sitio; en este sector se incluyen algunos adultos conocedores de la historia y defensores del patrimonio cultural.

b) Otra postura se advierte en algunos adultos entre 35 y 50 años. Aunque demuestran nociones sobre la importancia histórica del lugar y su reconocimiento para la historia nacional, sostienen otras consideraciones. Para este grupo, el CMSJ no debe estipularse solamente como sitio sagrado, porque posee otros usos y significados. Comparado con los ancianos del lugar, se notifican discursos -dígase gestos, afirmaciones y convicciones- diferentes. Para ellos, "los sitios históricos se conciben en cualquier país como pertenencia estatal, y no individual -por tantodebe ser el Estado el mayor velador por su salvaguarda y protección".

Obviamente, se revela un pensamiento donde el significado hacia el bien patrimonial marca otras pautas, desde luego, no solo el conocimiento proporciona sentido de apropiación del patrimonio como identidad colectiva, prevalecen expresiones que denotan estrechez por el significado solamente de tipo patrimonial, haciendo alusión a la necesidad de otros usos que también adquieren significados.

\footnotetext{
${ }^{28}$ Se alude al modelo ofrecido por Bonfil Batalla (2000) para estructurar el significado cultural.
} 


\section{Significado cultural del "Conjunto Monumentario San Juan" en la ciudad de Bayamo (Cuba). El doble discurso en las voces de los comunitarios}

La inclinación comunitaria que se desvía de la responsabilidad frente a la protección del patrimonio, también presenta otra lectura. Se trata de un comportamiento alejado del deber ciudadano que establece la política nacional, podría denominarse como una posición desentendida del rol que corresponde en el medio social comunitario, en tanto, prevalece quienes suponen el cuidado y protección de los bienes patrimoniales como tarea esencialmente institucional y estatal, sin considerar su participación activa dentro de la comunidad.

Desde esa mirada, sobresalen comportamientos inadecuados que atribuyen el patrimonio como "un bien que políticamente es de todos, pero en la práctica es de nadie", en esencia se trata de conductas que no han concientizado la necesidad de convertirse en actores activos de la comunidad, porque simplemente esperan por el esfuerzo exclusivo y representativo de las instituciones estatales; incluso expresan ilegal la toma de decisiones individuales para garantizar la preservación.

En esencia, tal problemática es resultado de insuficiencias por parte de las entidades, para integrar la gestión institucional en vínculo con la comunidad. Si bien en nuestro país la ideología de igualdad es una fortaleza, muy diferente resulta la práctica desacertada por miembros de la comunidad que no concientizan su rol en el cuidado del patrimonio.

c) Por otra parte, los adolescentes y jóvenes poseen un comportamiento más inclinado a su uso como lugar de esparcimiento social, para ellos el sitio no se concibe solamente como centralmente histórico y ceremonial. Aunque reconocen las características del lugar por las vivencias ceremoniales, educativas y patrióticas, consideran que el parque pudiera ser centro de otras acciones de esparcimiento y diversión.

Las nuevas generaciones aprecian el escenario para condecoraciones y celebraciones, y reconocen el sentido de identificación que poseen los más ancianos que viven en la remembranza del pasado glorioso; sin embargo, no conciben que la inclusión de otras actividades, degenere el valor patrimonial otorgado por años de vivencias históricas y patrióticas.

De forma general se evoca la importancia que presenta el sitio histórico para la comunidad, y se relaciona la valía patrimonial en evocación a la historia patria; entonces ¿a qué se debe la diversidad de criterios? ¿Qué influye en el significado diferente de cada grupo comunitario? Sin dudas, el significado guarda relación con el sentido de vida presente según las diferencias etarias, pero también influye la forma en que ha sido acogido el sitio de acuerdo con la multiplicidad de sus funciones, a lo largo de las diferentes etapas históricas.

Se distingue una integridad de significaciones que transcurren en el tiempo desde la etapa colonial, republicana y el actual contexto de revolución. En ese tránsito es visible el caudal de funciones que oscilan entre simbólicas y prácticas; se distinguen aquellas asociadas a la memoria histórica, a la formación de la identidad colectiva, el urbanismo y su espacio jerarquizado, la arquitectura religiosa, el arte escultórico, las funciones funerarias y el simbolismo de sacralidad. Con una connotación más 


\section{Yania Socarrás Montejo - Diurkis Yarenis Madrigal León - Alisa Natividad Delgado Tornes}

actual se aprecian las actividades educativas, políticas, y de esparcimiento cultural, donde el turismo adquiere un espacio central.

Una sistematización sobre el significado atribuido por los comunitarios, indican distinciones particularizadas a las funciones del sitio; así constan:

$\checkmark \quad$ Significado asociado a la configuración de la memoria histórica: Se reconoce como lugar trascendental dentro de la historia de la localidad y la nación, al rememorar sucesos patrióticos y personalidades de la cultura de trascendencia local y nacional. El sitio evoca acontecimientos cotidianos de la colonia y la república, de tipo religioso, funerario, artístico. Ello ha propiciado que toda acción destinada al lugar sea excusa para artículos periodísticos, reportajes televisivos, notas radiales y presencia en sitios digitales estatales o privados que rememoran la historia gloriosa de nuestra ciudad.

Para vecinos de la comunidad y bayameses en general, el CMSJ, constituye un lugar especial dentro de la historia local, se concibe como altar de la patria, al asociar el retablo con el homenaje de remembranza de aquellos que sacrificaron sus vidas para conseguir el bienestar de toda una nación.

La asociación con la historia patria indica para los más ancianos, la necesidad de comprender el sacrificio que debe ser perpetuado en la memoria de los más jóvenes, de manera que puedan incorporarlo como valor genuino. Para los adultos mayores no se trata solamente de la defensa de monumentos de piedra y metal, sino de la perseverancia de un sentimiento, de una convicción, de un alto simbolismo que implica respeto y sacralidad.

$\checkmark$ Significado asociado a la formación de la identidad colectiva: Más que una significación directa a un sujeto, ha formado parte de la identidad de la comunidad, las cotidianidades, las prácticas, las actitudes, denotan cómo ha ido tomando parte de sus vidas, incorporándolo a la historia de la comunidad y propiciando un sentido de pertenencia y relevancia en la identidad colectiva.

$\checkmark$ Significado asociado al simbolismo y sacralidad por su función funeraria: Con el paso del tiempo y aunque se hayan sumado nuevas funciones al sitio, este ha adquirido un carácter sagrado por la fuerte asociación como elemento material cultural y la creencia o actividad espiritual de un grupo y/o comunidad en el pasado. Como era costumbre durante la colonia en el interior y exterior de las iglesias se realizaban servicios fúnebres. Por necesidad de higienización del espacio, se construyó en este sitio el Primer Cementerio al aire libre de Cuba. Se delimitaron así las primeras funciones sociales marcadas por las necesidades funerarias de la época, en ello residió el carácter utilitario para la ciudad colonial.

Quizá este sea el aspecto más devaluado en la actualidad, que ha provocado la reacción defensiva en aquellos que aún la comparten. Las discrepancias en torno a este significado, difiere entre jóvenes y ancianos; de igual modo, los gestos de pasividad por una parte considerable de los adultos indica que la percepción del sitio como baluarte sacro no es compartido por todos, máxime cuando se ejecutan 


\section{Significado cultural del "Conjunto Monumentario San Juan" en la ciudad de Bayamo (Cuba). El doble discurso en las voces de los comunitarios}

actividades ${ }^{29}$ facilitadas por instituciones culturales y deportivas en las áreas cercanas a los monumentos.

La realidad indica la resistencia a posicionamientos más conservadores, tras la llegada de nuevos usos avalados por significados que se aferraran a nuevas prácticas sociales y culturales con imagen de modernidad. De ahí la controversia entre los significados atribuidos para los residentes del lugar, en un debate contrapuesto que se proyecta entre lo venerado y lo funcional. Solamente los ancianos y pocos adultos insisten en el significado del sitio como eminentemente sagrado, mientras los más jóvenes se inclinan por su utilidad.

$\checkmark$ Significado asociado a la arquitectura religiosa: Desde su surgimiento el sitio estuvo vinculado a la Iglesia San Juan Evangelista, considerada como la segunda iglesia de importancia en Bayamo. Su torre fue anexada en el siglo XIX, y luego quemada en el incendio de 1869, desde entonces se convirtió en el segundo símbolo de la arquitectura religiosa de la etapa colonial, después de la Parroquial Mayor San Salvador de Bayamo. La asociación con este significado es más puntual entre personas adultas, quienes de una forma u otra han ejercido laboralmente en esta esfera, $y$, por tanto, argumentan la necesidad de que sea reconocido este valor por la comunidad en su conjunto.

$\checkmark$ Significado asociado al arte escultórico: Allí se encuentra la única escultura funeraria del Primer Cementerio al aire libre de Cuba, el San Juan Evangelista. En épocas posteriores se realizaron nuevos monumentos funerarios respectivos a Francisco V. Aguilera, José Joaquín Palma y treinta y tres rostros ${ }^{30}$ en altorrelieves, cubiertos en mármol blanco representativos de patriotas bayameses hombres y mujeres, vinculados con el proceso independentista cubano. La valía escultórica se denota más por la visibilidad que ocupa en el entorno, se convierte así en una señal que indica un alto ante la mirada de comunitarios y visitantes. Aunque revelan majestuosidad y faro de patriotismo para todos los bayameses, el empeño por su protección sigue impregnado en las voces de los más ancianos del recinto.

$\checkmark$ Significado asociado al urbanismo: Las valoraciones de significatividad muestran un uso frecuente y activo del CMSJ, debido a la amplitud del perímetro y la posición de las calles que lo conforman. Estas particularidades le convierten en un espacio urbano jerarquizado de fácil ubicación para bayameses y visitantes. La mayoría de los entrevistados y encuestados consideran que el lugar constituye un símbolo

\footnotetext{
${ }^{29}$ Las actividades se caracterizan por juegos deportivos para niños y adolescentes.

30 En su mayoría son próceres y mártires de la gesta independentista, figuran a la izquierda de F. V. Aguilera: Jorge Carlos Milanés, Pedro Maceo Chamorro, Rdo. Padre Baptista, Lucas del Castillo Moreno, José Joaquín Palma Lasso de la Vega, José M. Izaguirre, Joaquín Acosta, Dr. Diego Tamayo Figueredo, Juan Clemente Zenea, Esteban Estrada, Antonio Yero, Máximo Gómez Báez, Luis Marcano, Manuel de Jesús Calvar y Odoardo (Tita Calvar), José Manuel Capote Sosa y Tomás Estrada Palma. A la derecha de F. V. Aguilera: Candelaria Figueredo Vázquez, Luz Vázquez y Moreno, Candelaria Palma, Adriana del Castillo, Paulita Téllez, Átala del Castillo, Fernando Figueredo Socarrás, Francisco Javier de Céspedes y del Castillo, Donato del Mármol Tamayo, Ramón C. Fornaris, Emiliano Tamayo, Carlos Manuel de Céspedes y del Castillo, Pedro Figueredo Cisnero, Francisco Maceo Osorio, José Fornaris, Ismael de Céspedes y Yero y Oscar de Céspedes y Céspedes.
} 


\section{Yania Socarrás Montejo - Diurkis Yarenis Madrigal León - Alisa Natividad Delgado Tornes}

distintivo que permite orientar a los desconocidos, al tiempo que lo colocan en una posición específica frente a otros espacios de la ciudad.

$\checkmark$ Significado asociado a las actividades políticas: Debido al propio carácter de monumento conmemorativo erigido a la memoria de personalidades de las gestas independentistas, el CMSJ se convirtió en un espacio abierto apto para el desarrollo de actos públicos con carácter político y de reafirmación revolucionaria, reconocido por todos los grupos etarios. Todos los años se realizan marchas, actos, desfiles y jornadas políticas a favor del proceso revolucionario cubano.

$\checkmark$ Significado asociado a las funciones educativas: Constituye escenario para la realización de actos públicos donde se convocan a estudiantes de las distintas enseñanzas, para participar en las acciones patrióticas, cumpliendo así una función formativa e instructiva, mayormente reconocida por el sector pedagógico de la ciudad y la provincia.

$\checkmark$ Significado asociado a las funciones de esparcimiento cultural: Dentro de los cambios de significados que experimentan los sitios patrimoniales cabe destacar que se encuentran aquellos respectivos al valor de uso. Para este caso se advierten funciones festivas en los alrededores del sitio que fueron realizadas desde mediados del siglo XX de la etapa republicana; así constan la llamada "Feria de las Flores" vista como celebración tradicional de la ciudad. También se incluyen otras prácticas realizadas por niños y adolescentes, quienes asumen el espacio como parque para encuentros dinámicos y divertidos.

$\checkmark$ Significado asociado al turismo: Todos los significados en su conjunto, son relevantes en la interpretación y guía del turismo nacional e internacional, por lo cual el Ministerio de Turismo ha concebido la visita al sitio como parte de las rutas relevantes al interior de la ciudad. Los plegables entregados a turistas en la Oficina de INFOTUR, dan prioridad en su carátula al sitio histórico en una imagen alegórica al sitio.

La utilidad del sitio, otorga puntos al significado valorado por la diversidad y la diferencia. Así los más jóvenes aluden al esparcimiento cultural, mientras los mayores se aferran a la solemnidad del carácter patrio. En consecuencia, tanto las políticas como sus implementaciones deben estar en correspondencia con un manejo integral del sitio, que reevalúe las ventajas y desventajas a fin de dignificar al CMSJ en la multitud del significado cultural.

El CMSJ como patrimonio de la comunidad, representa multitud de significados, no solo por los grandes acontecimientos acaecidos en el pasado, sino por esa historia menor y colectiva, en el devenir paulatino de vivencias, relaciones sociales, creencias y alegrías de la cotidianidad, que también definen la herencia histórica y la identidad colectiva del presente.

La dimensión humana y social del patrimonio cultural le convierte verdaderamente en significativo, sin ella el patrimonio carece de valor y por lo tanto de sentido. La apropiación que hace la comunidad del patrimonio denota su constitución como elemento de identidad, no se trata de hacer valer por fuerza su reconocimiento desde lo institucional o desde las posiciones políticas y gubernamentales, sino 


\section{Significado cultural del "Conjunto Monumentario San Juan" en la ciudad de Bayamo (Cuba). El doble discurso en las voces de los comunitarios}

avalado por la comunidad, quien reconozca, se pronuncie y actúe a favor de la protección.

Un aspecto para reconsiderar concierne a la implementación de la política cultural, en ello se advierten incongruencias; aunque, por un lado, la política cultural prioriza en sus leyes y decretos la defensa del patrimonio de la nación, por otra parte, no se concretan prácticas institucionales que respondan coherentemente con la participación comunitaria como la mayor protectora del entorno que hace distintivo su valor. Si consideramos que son las prácticas modelos de actuación y reflejo de una ética, estas deben estar en correspondencia con la política establecida.

Si bien, las prácticas y políticas pueden enriquecer una cultura, el peligro también está en que pueden transformarla y perjudicarla en tanto la cultura es cambiante, sujeta siempre a transformaciones. En ello tributa la defensa de la identidad colectiva y de aquellos valores más enriquecedores de la cultura, por tanto, debe ser prioridad a fin de articular las nuevas prácticas y las políticas en un entorno coherente para las nuevas generaciones.

Resulta imprescindible esa sensibilidad de aquel que otorga significado, convirtiéndole en elemento significativo y simbólico, ineludible a la hora de narrar la historia y de recorrer el entorno de una comunidad. Para ello es necesario ese desvelo por el conocimiento de sus valores históricos, artísticos, las posiciones en el entorno y la intencionalidad de dignificar personalidades o acontecimientos, en el intento de perpetuar la memoria de una localidad o nación. No se trata de una mera construcción objetiva y material, sino de aquello en que ha logrado convertirse parte de una identidad.

\section{Consideraciones finales}

La apreciación del patrimonio cultural siguiendo los objetos según su valor (arquitectónico, artístico, etc.) ha sido puntualmente necesaria, pero no justifican en sí la defensa de los mismos. Ello fundamenta la necesidad de nuevas perspectivas para reconocer el bien patrimonial sobre la base del significado cultural adquirido. La significación cultural es un eje vinculado al proceso identitario. Interviene la conciencia del individuo al reconocerse en su propio entorno, así existe, en tanto, permite la identificación consciente con aquellos bienes y valores distintivos de otros territorios; no obstante, se precisan nuevos factores entretejidos sobre la base del conocimiento, la apropiación y protección.

El caso del CMSJ, presenta una polémica compleja. El significado cultural adquiere connotación atendiendo a los niveles de relevancia que otorgan sus pobladores, pasando por el valor simbólico, hasta llegar al valor de uso, y expresado de manera diversa y jerárquica; en ello intervienen las funciones y significados presentes en la pluralidad de sus habitantes, según la estructura social y etaria. Por tanto, las normas y las reglas de conducta se van a expresar en símbolos, que al compartirlos exige la comprensión de un grupo de significantes comunes, aun cuando existan otros no compartidos. 


\section{Yania Socarrás Montejo - Diurkis Yarenis Madrigal León - Alisa Natividad Delgado Tornes}

Para comprender la multiplicidad de apropiaciones de acuerdo con los usos, en el caso del CMSJ, es preciso partir de la dinámica social, y las transformaciones dialécticas acaecidas en consecuencia con el contexto socioeconómico y cultural. Se trata de elementos que intervienen en la multiplicidad de valoraciones respecto al mismo espacio patrimonial. La realidad indica la necesidad de concebir el valor de uso atendiendo los cambios del entorno comunitario, sin descuidar el conocimiento y la concientización del bien patrimonial.

La preocupación genuina de algunos comunitarios por direccionar mayor atención al CMSJ, hablan, per se, de las posiciones para otorgar relevancia al significado cultural. No obstante, se precisan nuevas estrategias integradas para implicar la comunidad de forma más participativa y consciente de su rol en la conservación del bien patrimonial.

\section{Bibliografía}

Bonfil Batalla. Nuestro Patrimonio Cultural: un Laberinto de Significados. Revista Mexicana de Estudios Antropológicos. México, ed. Sociedad Mexicana de Antropología, Vol. XLV-XLVI, 2000.

Carlos Andrés Pinassi y Miguel Seguí. "Representación del espacio urbano en alumnos de primaria de la ciudad de Bahía Blanca (Argentina). Un análisis a partir de mapas mentales". Boletín de la Asociación de Geógrafos Españoles, №72, 2016, pp.349-380. DOI: 10.21138/bage.2344

Carlos Andrés Pinassi. “Análisis de las estrategias de gestión urbano-patrimonial en el centro histórico de Bahía Blanca” Párrafos Geográficos, Vol. 10, № 1, 2011, pp. 407-430.

Carlos Andrés Pinassi. "Los adolescentes de la ciudad de Bahía Blanca (Rep. Argentina) y el vínculo con el patrimonio cultural: ¿es posible hablar de un espacio vivido patrimonial?" Lurralde: inves. espac. $\mathrm{N}^{\circ} 41,2018$, pp. 55-91

Carlos Andrés Pinassi. "Valorización social del patrimonio cultural de la ciudad de Bahía Blanca. La mirada de los residentes adultos”. Párrafos Geográficos, Vol. 16, $\mathrm{N}^{\circ} 1,2017$.

Clifford Geertz. "Descripción densa: hacia una teoría interpretativa de la cultura"; en Alain Basail Rodríguez y Daniel Álvarez Durán. Sociología de la cultura. Selección de Lecturas. Barcelona, Editorial Paidós, 2004. 


\section{Significado cultural del "Conjunto Monumentario San Juan" en la ciudad de Bayamo (Cuba). El doble discurso en las voces de los comunitarios}

Comité Científico Internacional del ICOMOS. Carta ICOMOS para Interpretación y Presentación de Sitios de Patrimonio Cultural.16 a Asamblea General del ICOMOS, Québec, Canadá, 2008.

Daniel Mato. Estudios y otras prácticas intelectuales latinoamericanas en cultura y poder. Buenos Aires, CLACSO, 2002.

Gregorio Rodríguez Gómez, Javier Gil Flores, Eduardo García Jiménez. Metodología de la Investigación cualitativa. La Habana, Editorial Félix Varela, 2004.

Idelmis Mari Aguilera y Eduardo Aguilera. Entre el batey y el parque, las plazas. Bayamo, Ediciones Bayamo, 2005.

Jeffrey Alexander. Sociología Cultural. Formas de clasificación de las sociedades complejas. Vol.1. México, Anthropos Editorial, 2000.

José Ignacio Ruíz Olabuénaga. Metodología de la Investigación cualitativa. España, Universidad de Deusto, Bilbao, 1999.

Ley No.1 Ley de Protección al Patrimonio Cultural y No.2 Ley de Monumentos Nacionales y Locales (1977), la Ley No.62 Código Penal (1987) y Ley 81 Del Medio Ambiente y un conjunto de decretos y resoluciones (1997). Constitución de la República de Cuba. 1976

Llorenc Prats. "Concepto y gestión del patrimonio local" Cuadernos de Antropología Social, N²1, 2005, pp. 17-35.

Llorenc Prats. "El concepto de patrimonio cultural”. Política y Sociedad, N²7, 1998, pp.63-76

Lourdes de Urrutia Torres y Graciela González Olnedo. Metodología de la Investigación social 1 y 2. Selección de Lecturas. La Habana, Editorial Félix Varela, 2003

Ludín Fonseca. Bayamo en la Modernidad. Cementerios y enterramientos. Bayamo, Ediciones Bayamo, 2005.

María Eugenia Conforti, Mercedes Mariano y Micaela Baier. "La gestión del patrimonio: entre la horizontalidad y la verticalidad. Un caso de estudio en provincia de Buenos Aires, Argentina". Jangwa Pana, Vol.19, $\mathrm{N}^{\circ} 3,2020$. Doi: https://doi.org/10.21676/16574923.3714

Martín Barbero. "Dinámicas Urbanas de la Cultura”. Ponencia presentada en el seminario La ciudad: cultura, espacios y modos de vida, Medellín. Gaceta de Cultura, No. 12, Dic., Ed. Instituto Colombiano de Cultura, 1991. 


\section{Yania Socarrás Montejo - Diurkis Yarenis Madrigal León - Alisa Natividad Delgado Tornes}

Mónica Lacarrieu Cicchetti. “¿Es necesario gestionar el patrimonio inmaterial? Notas y reflexiones para repensar las estrategias políticas y de gestión”. Boletín de Gestión Cultural, N¹7, 2008, pp. 1-26.

Nestor García Canclini y M. Piccini. "Culturas de la ciudad de México: símbolos colectivos y usos del espacio urbano". El consumo cultural en México. México, D.F: CNCA, 1993.

Nestor García Canclini. "Los Usos Sociales del Patrimonio Cultural”. Patrimonio Etnológico. Nuevas Perspectivas de Estudio. Sevilla, Instituto Andaluz del Patrimonio Histórico, 1999.

Pierre Bourdieu. "Entrevista a Pierre Bourdieu: La lógica de los campos". Zona Erógena, No 16. Buenos Aires, 1993.

Pierre Bourdieu. Sociología y cultura. México, D.F.: Grijalbo-Consejo Nacional para la Cultura y las Artes, 1990.

Roberto Hernández Sampier, C Fernández-Collado y P Baptista Lucio. Metodología de la investigación (4ta. Ed.). México. Ed. McGraw-Hill Interamericana, 2006

Stuart Hall, “¿Quién necesita la identidad?” Temas No. 37-38. Abril-Sept, 2004.

UNESCO. Documentos área cultural: wwww.unesco.org/cultura/es Carta de Atenas (1934), Carta Internacional sobre la conservación y la restauración de monumentos y conjuntos históricos-artísticos (1964), Carta de Venecia (1964), Convención del Patrimonio Mundial (1975), Carta de Burra, Australia, para Sitios de Significación Cultural (1979), Convención de Granada (1985), Normas de Quito (1987), Carta de Washington (1987), Carta de Cracovia (2000), Carta ICOMOS Principios para el análisis, conservación y restauración de las estructuras del Patrimonio Arquitectónico (2003). Carta de Cracovia (2000). Principios para la conservación y restauración del Patrimonio construido. Cracovia. Comité de redacción de los directores de áreas. Carta Cultural Iberoamericana (2006). Carta de Brasilia (1995).

Victoria Quintero Moron y Cristina Sánchez Carretero. "Los verbos de la participación social y sus conjugaciones: contradicciones de un patrimonio democratización".

Revista Andaluza de Antropología, N²12, 2017, pp. 48-69.

Yania Socarrás Montejo. Aproximación al estudio histórico estético de la actual necrópolis de Bayamo. Trabajo de Diploma, ejercicio de culminación de estudios de pregrado Universidad de Oriente, Santiago de Cuba, 2005.

Recibido: 07/10/2020

Evaluado: $30 / 11 / 2020$

Versión Final: 14/12/2020 